\title{
The optimization design of Piled raft foundation for substation building in US code
}

\author{
Yang Qingtao*1, Chen Ying ${ }^{1}$, Li Wei $^{1}$, Wei Xiao ${ }^{1}$, Gan Xing $^{2}$ \\ ${ }^{1}$ State Nuclear Electric Power Planning Design \& Research Institute, Beijing 100095, china; \\ ${ }^{2}$ Construction Branch of State Grid Xinjiang Electric Power Co., Ltd, Urumqi 830002, china
}

\begin{abstract}
In order to get a more safety and economic foundation, finite element method was performed for a piled mat cap and piled strip cap by the software of STAAD. Through the finite element analysis, plate distribution region of bending moment and shear stress were researched; meanwhile, considering the compatibility of deformation of element plate, how to chose the design value of plate stress was researched. The result showed that: single plate value is not representative, average of value of 9 plates ( $3 \times 3$ array) is close to the fact. Strip cap is better than mat cap both from the moment value and shear value of plate element in this project; strip cap was recommended due to its remarkable economic benefit.
\end{abstract}

\section{Introduction}

Substation building is an essential facility in the substation, which ensures the reliability of urban power supply. Figure 1 is a building of $230 \mathrm{kV}$ substation in the Philippines. The substation building is a fifth-layer concrete frame structure, which is 26.8 meters high. $230 \mathrm{kV}$ gantry on the top of substation building, which is 21 meters high. Pile foundation was used in substation building. Pile arrangement and pile cap types were the major work for the engineer designer ${ }^{[1]}$.

\section{Design input condition}

\subsection{Wind load}

1) Wind load maximum wind speed (3seconds gust speed at $10 \mathrm{~m}$ height above soil) is $75 \mathrm{~m} / \mathrm{s}$.

2) Exposure category D.

3) Structure Category II.

4) Gust effect factor $G=0.85$.

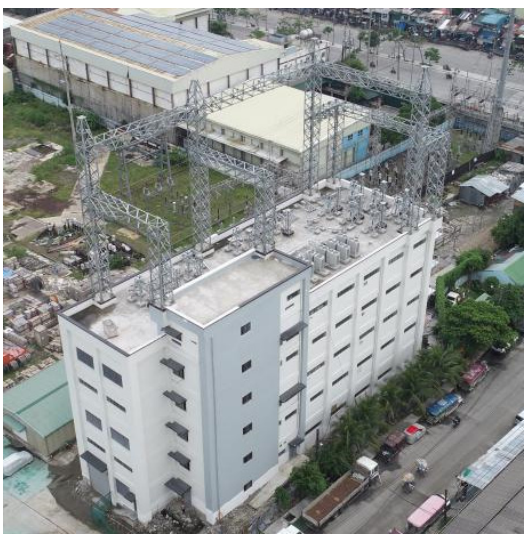

Figure 1. substation building in the Philippines

\subsection{Seismic loads}

Seismic zone factor $Z=0.4$, Soil type $S_{D}$, Seismic source type B.

$\mathrm{R}$ (response modification factor) for substation building the structure system should choose Special moment-resisting frame, the value of $\mathrm{R}$ is 8.5 ; refer to steel supports (non-buildings structures not similar to buildings), proposed $\mathrm{R}$ will be 3 for gantries ${ }^{[2]}$.

\subsection{Load combinations}

This project was suggested to design with US code, both Ultimate Limit State and Serviceability Limit State should be considered in piled raft foundation design ${ }^{[3]}$. The ULS and SLS load general combinations according to contractual specifications are based on ASCE7-10. 


\subsection{Pile parameter}

This project uses pile foundation. Type of the pile and single pile capacity are shown in the following:

Type of pile : cast-in-situ bored pile.

Pile diameter: $800 \mathrm{~mm}$.

Allowable compressive capacity: $1340 \mathrm{kN}$.

Allowable tensile capacity: $615 \mathrm{kN}$.

Allowable lateral capacity: $70 \mathrm{kN}$.

\section{Calculation principle $e^{[4-6]}$}

Staad Pro V8i(SS6) software shall be adopted for substation building structure analysis and design. The strength design and allowable stress design were adopted for the analysis. The STAAD plate finite element is based on hybrid finite element formulations. A complete quadratic stress distribution is assumed. For plane stress action, the assumed stress distribution is as follows.

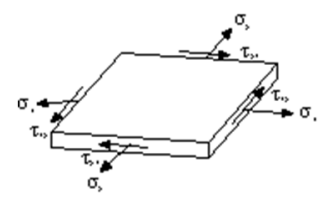

Figure 2. Assumed stress distribution

$$
\left(\begin{array}{c}
\sigma_{x} \\
\sigma_{y} \\
\tau_{x y}
\end{array}\right)=\left[\begin{array}{cccccccccc}
1 & x & y & 0 & 0 & 0 & 0 & x^{2} & 2 x y & 0 \\
0 & 0 & 0 & 1 & x & y & 0 & y^{2} & 0 & 2 x y \\
0 & -y & 0 & 0 & 0 & -x & 1 & -2 x y & -y^{2} & -x^{2}
\end{array}\right]\left(\begin{array}{c}
a_{1} \\
a_{2} \\
a_{3} \\
\vdots \\
a_{10}
\end{array}\right)
$$

Figure 3. Complete quadratic assumed stress distribution

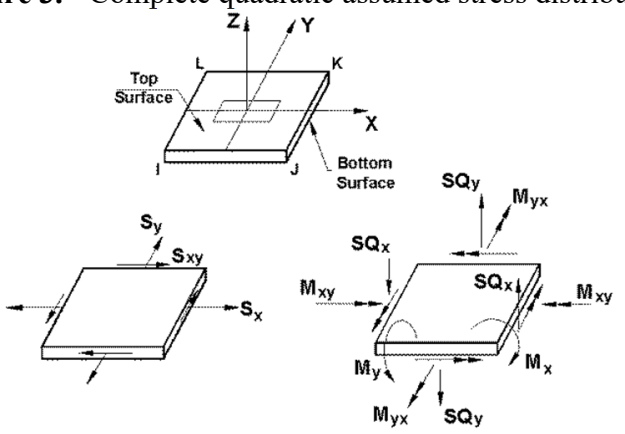

Figure 4. Sign convention of element forces Sqx, Sqy : Shear stresses (Force/ unit len./thk.) Sx, Sy, Sxy: Membrane stresses (Force/unit len./thk)

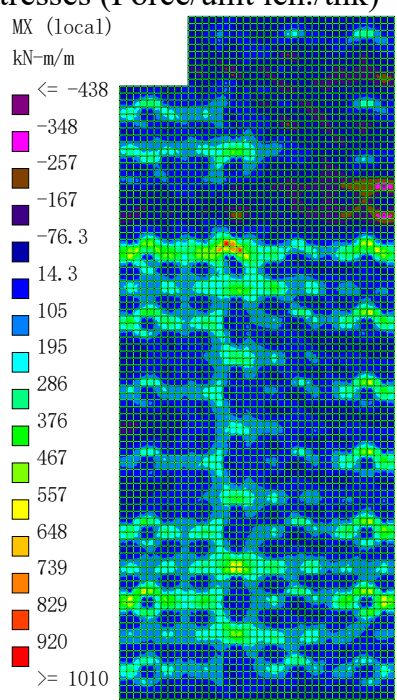

Mx, My, Mxy: Bending moments per unit width (Moment/unit len.)

\section{Project Design}

The customer suggest us use mat pile cap. We wanted to optimize the pile cap.So we suggest two schemes to piled raft cap design of substation building. One is mat cap ,another is strip cap. The analysis model is shown in the following figure.

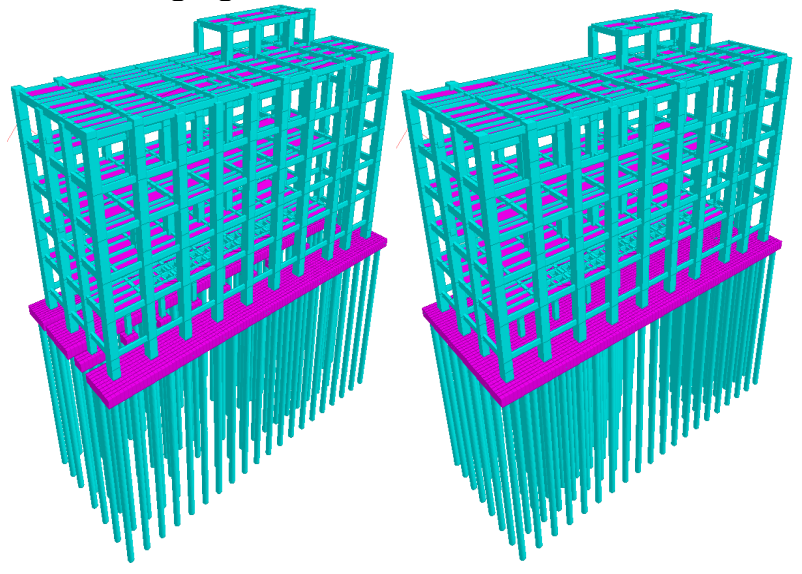

Figure 5. Two schemes model for substation building

The parameter of pile and pile cap is shown in the following table. In order to get accurate result, cap plates were meshed to square plate element, which is $0.5 \mathrm{~m} \mathrm{x}$ $0.5 \mathrm{~m}$.

Table1. Two schemes model for substation building

\begin{tabular}{|l|l|l|}
\hline Parameter & Mat & Strip \\
\hline pile number & 156 & 137 \\
\hline cap area & $955 \mathrm{~m}^{2}$ & $756.2 \mathrm{~m}^{2}$ \\
\hline cap thickness & $1.1 \mathrm{~m}$ & $1.1 \mathrm{~m}$ \\
\hline meshing size & $0.5 \mathrm{~m}$ & $0.5 \mathrm{~m}$ \\
\hline
\end{tabular}

\subsection{Bending moment}

The result of bending moment for piled raft cap is shown in the following figure.

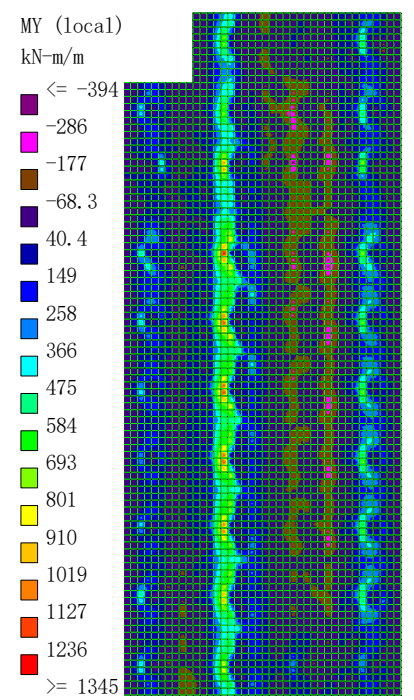

Figure 6. Color nephogram of bending moment $\mathrm{Mx}$ and My for mat cap 

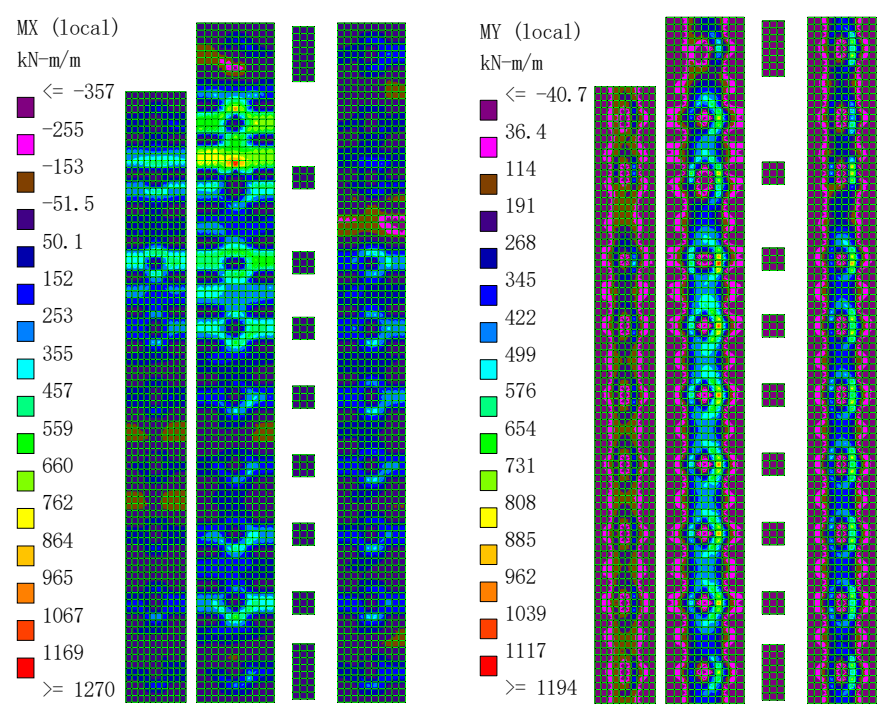

Figure 7. Color nephogram of bending moment $\mathrm{Mx}$ and My for strip cap

Table2. Maximum value of bending moment

\begin{tabular}{|c|c|c|}
\hline \multirow{2}{*}{ Moment } & Mat & Strip \\
\cline { 2 - 3 } & \multicolumn{2}{|c|}{$(\mathrm{kN}-\mathrm{m} / \mathrm{m})$} \\
\hline Mx-top & 1010 & 1270 \\
\hline Mx-bot & -438 & -540 \\
\hline My-top & 1345 & 1194 \\
\hline My-bot & -671 & -224 \\
\hline
\end{tabular}

We used the Wood-Armer equations for reinforcement calculations $^{[7]}$, as follows:Mx, My, and Mxy are calculated, by STAAD. They are used to compute the values of design moments, Mxd and Myd.

For top reinforcement, we computes:

$\mathrm{Mx} 1=\mathrm{Mx}+\operatorname{abs}(\mathrm{Mxy})$

My1 $=$ My $+\operatorname{abs}($ Mxy)

$\mathrm{Mx} 2=\mathrm{Mx}+\operatorname{abs}($ Mxy2 / My)

My2 $=$ My $+\operatorname{abs}($ Mxy2 $/$ Mx $)$

If both Mx1 and Myl are positive, Mxd = Mx1 and Myd $=$ My1.

If both Mx1 and Myl are negative, Mxd = 0 and Myd $=0$.

If Mx1 is negative and Myl positive, $\mathrm{Mxd}=0$ and Myd $=$ My2.

If My1 is negative and Mx1 positive, $\mathrm{Mxd}=\mathrm{Mx} 2$ and $\operatorname{Myd}=0$.

For bottom reinforcement:

Mx1 = Mx - abs(Mxy)

My1 $=$ My $-\operatorname{abs}($ Mxy)

Mx2 $=$ Mx $-\operatorname{abs}($ Mxy2 / My)

My2 = My - abs(Mxy2 / Mx)

If both Mx1 and Myl are positive, Mxd = 0 and Myd $=0$.

If both Mx1 and My1 are negative, Mxd = Mx1 and $\operatorname{Myd}=$ Myl.

If $\mathrm{Mx} 1$ is negative and My1 positive, $\mathrm{Mxd}=\mathrm{Mx} 2$ and Myd $=0$.

If Myl is negative and Mxl positive, $\mathrm{Mxd}=0$ and Myd $=$ My2.

Table3. Maximum value of bending moment for design

\begin{tabular}{|c|c|c|}
\hline Moment & Mat & Strip \\
\hline
\end{tabular}

\begin{tabular}{|l|c|c|}
\hline & \multicolumn{2}{|c|}{$(\mathrm{kN}-\mathrm{m} / \mathrm{m})$} \\
\hline Mxd-top & 1094 & 1279 \\
\hline Mxd-bot & -499 & -599 \\
\hline Myd-top & 1382 & 1424 \\
\hline Myd-bot & -710 & -285 \\
\hline
\end{tabular}

The color nephogram of bending moment showed that only a few moment value of plates reached the maximum value. Consider the compatibility of deformation of element plate, the average of value of nearest 9 plates $(3 \times 3$ array) was performed as the design value conservatively, which made the calculate results close to the fact.

Table4. Max plate bending moment $(\mathrm{kN}-\mathrm{m} / \mathrm{m})$

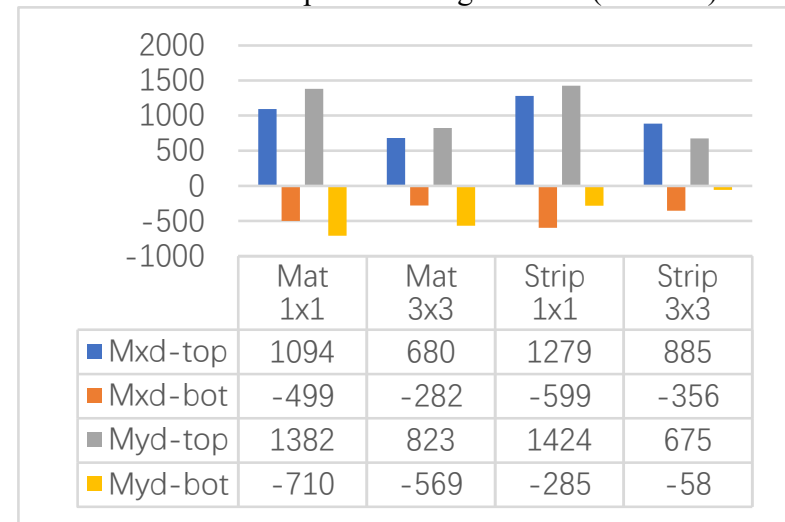

From the table above, mat cap plate top value of moment are 823 and 680 , strip cap plate top value of moment are 885 and 675 . The moment on the top plate of Strip cap increase $7.5 \%$ than the moment of mat cap. Mat cap plate bottom value of moment are -569 and -282 , strip cap plate top value of moment are -356 and -58 . The moment on the bottom plate of Strip cap reduce $37.4 \%$ than the moment of mat cap. Strip cap is better than mat cap from the moment value of plate element.

\subsection{Shear stress}

The result of shear stress for piled raft cap is shown in the following figure. 

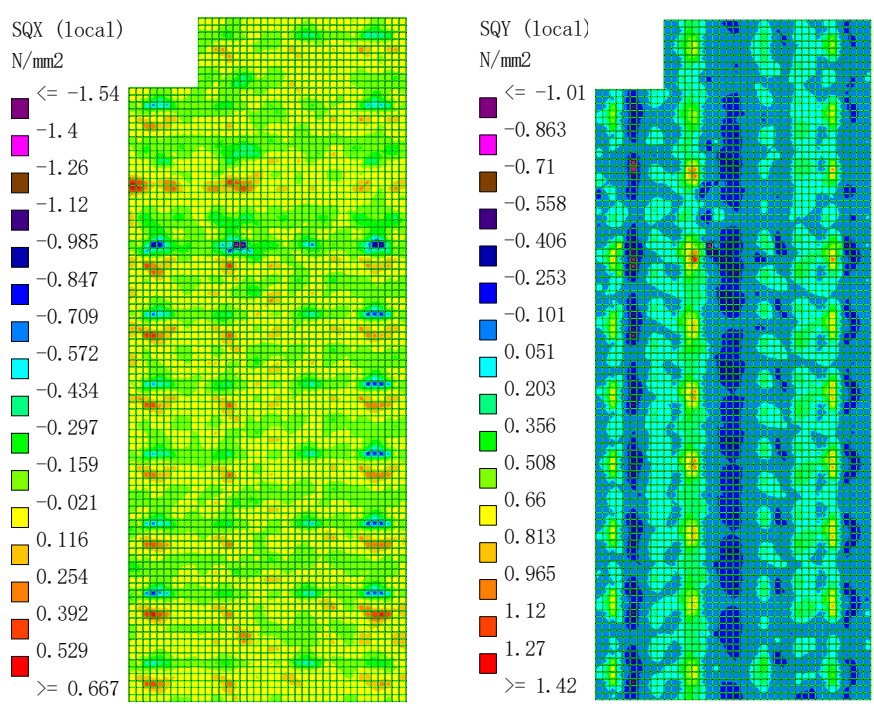

Figure 8. Color nephogram of shear stress Sqx and Sqy for mat cap

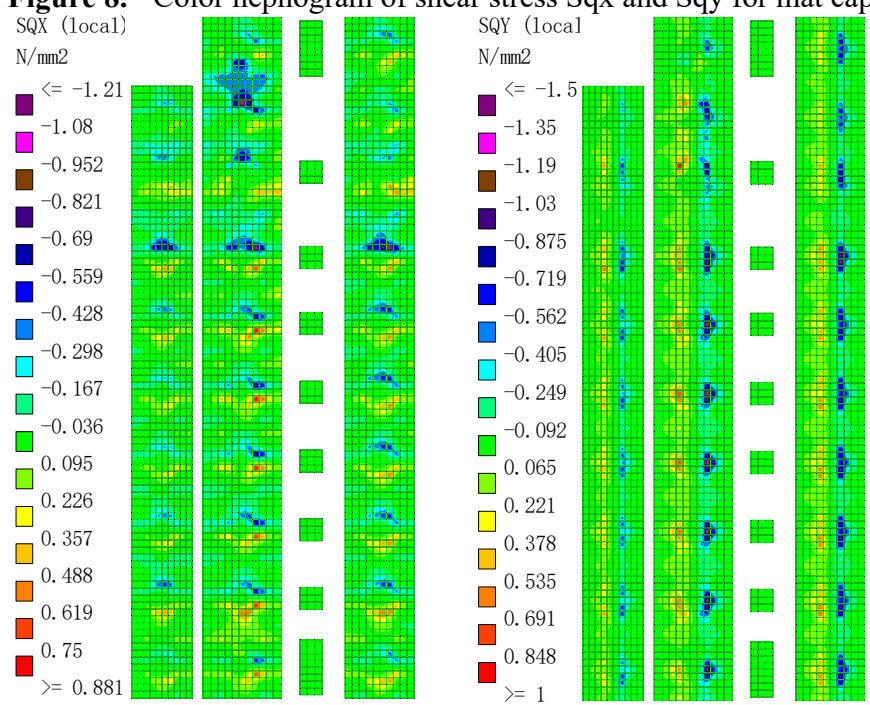

Figure 9. Color nephogram of shear stress Sqx and Sqy for strip cap

The color nephogram of shear stress showed that only a few stress value of plates reached the maximum value. Consider the compatibility of deformation of element plate, the average of value of nearest 9 plates ( $3 \times 3$ array) was performed as the design value conservatively, which made the calculate results close to the fact.

From the table below, mat cap plate top value of shear stress are 0.74 and 0.57 , strip cap plate top value of shear stress are 0.6 and 0.45 . The shear stress on the top plate of Strip cap reduce $18.9 \%$ than the shear stress of mat cap. Mat cap plate bottom value of shear stress are -0.73 and 0.64 , strip cap plate top value of shear stress are -0.65 and -0.64 . The shear stress on the bottom plate of Strip cap reduce $11.0 \%$ than the shear stress of mat cap. Strip cap is better than mat cap from the shear stress value of plate element.

Table5. Max plate shear stress $\left(\mathrm{N}-/ \mathrm{mm}^{2}\right)$

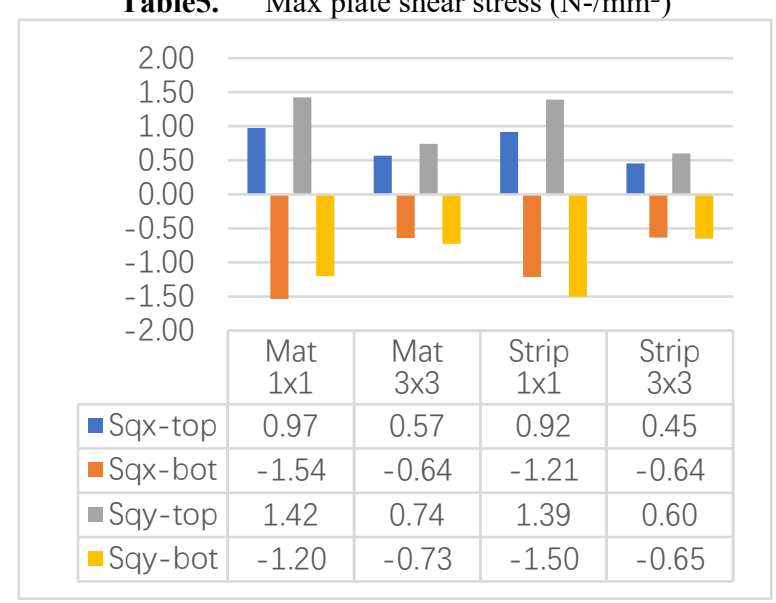

\section{Result}

1) single plate value is not representative, average of value of 9 plates ( $3 \times 3$ array) is close to the fact.

2) The moment on the top plate of Strip cap increase $7.5 \%$ than the moment of mat cap. The moment on the bottom plate of Strip cap reduce $37.4 \%$ than the moment of mat cap. Strip cap is better than mat cap from the 
moment value of plate element.

3)The shear stress on the top plate of Strip cap reduce $18.9 \%$ than the shear stress of mat cap. The shear stress on the bottom plate of Strip cap reduce $11.0 \%$ than the shear stress of mat cap. Strip cap is better than mat cap from the shear stress value of plate element.

4) Strip cap reduce $20.8 \%$ reinforcement concrete than mat cap. We recommend strip cap in the project due to its remarkable economic benefit.

\section{Acknowledgments}

This work is supported by Shared Application on Transmission \& Distribution Project and 5G Communication Technology project. This support is greatly appreciated.

\section{References}

1. Leon Kempner,Jr. 2007 Substation Structure Design Guide, American Society of Civil Engineers P101.

2. Uniform Building Code 1997 Structural Engineering Design Provisions .Volume 2 P56

3. Minimum Design Loads for Buildings and other Structures(ASCE7-10) 2010 American Society of Civil Engineers P7.

4. Russo G 1998 Numerical analysis of piled rafts. Int J Nume Anal Mech Geomech, P477.

5. Chow Y K, Yong K Y,Shen W Y. 2001 Analysis of piled raft foundations using a variational approach. The International Journal of Geomechanics, P129.

6. Zhu Bo-fang. 1998 The finite element method theory and application, Water Conservancy and Hydropower Press, P132

7. Joseph E.Bowles, P.E.,S,E. 1997 Foundation analysis and design. P1027. 